\title{
High-resolution topography for Digital Terrain Model (DTM) in Keller Peninsula, Maritime Antarctica
}

\author{
ADRIANO L. SCHÜNEMANN ${ }^{1}$, PEDRO HENRIQUE A. ALMEIDA ${ }^{2}$, ANDRÉ $^{2}$ \\ THOMAZINI ${ }^{3}$, ELPÍDIO I. FERNANDES FILHO ${ }^{2}$, MÁRCIO R. FRANCELINO ${ }^{2}$, \\ CARLOS E.G.R. SCHAEFER ${ }^{2}$ and ANTONIO BATISTA PEREIRA ${ }^{1}$
}

\author{
${ }^{1}$ Universidade Federal do Pampa/UNIPAMPA, Avenida Antônio Trilha, 1847, 97300-000 São Gabriel, RS, Brazil \\ ${ }^{2}$ Universidade Federal de Viçosa/UFV, Avenida Peter Henry Rolfs, s/n, Campus Universitário, 36570-900 Viçosa, MG, Brazil \\ ${ }^{3}$ Universidade Federal de São João Del-Rei/UFSJ, Departamento de Ciências Agrárias/DCIAG, Rua Sétimo \\ Moreira Martins, 188, Bairro Itapoã, Caixa Postal 56, 35702-031 Sete Lagoas, MG, Brazil
}

Manuscript received on April 25, 2017; accepted for publication on July 27, 2017

\begin{abstract}
High resolution topography (HRT) surveys is an important tool to model landscapes, especially in zones subjected to strong environmental changes, such as Antarctica, where landform is highly influenced by cryoclasty and permafrost melting. The aim of this work was to obtain a high accurate DTM for Keller Peninsula, Maritime Antarctica. The survey study was assessed in the 2014/2015 and 2015/2016 during the austral summer, by using Terrestrial Laser Scanner (TLS). In order to cover $8 \mathrm{~km}^{2}$ of the Peninsula, the TLS equipment was installed in 81 different points. Results of the DTM generated by TLS (hereafter, HRT-DTM), and the terrain variables Aspect, Slope and Hillshade obtained were compared with previous models generated by aerophotographic survey (hereafter, APG-DTM). RMSE for the HRT and APG-DTM were 0.726 and $2.397 \mathrm{~m}$, respectively. Spatial resolution of the DTMs was $0.20 \mathrm{~m}$. Morphometric variables obtained from the two methods presented visual differences on the thematic maps, especially related to the Aspect. Generalization was the main process, whereas interpolation occurred for the HRT survey, being the process of choice for the APG method. A large number of points are obtained by the TLS, providing a dense cloud of points, spatially well-distributed, enabling the generalization process to obtain surface models with high performance.
\end{abstract}

Key words: terrestrial laser scanner, remote sensing, geomorphology, Antarctic.

\section{INTRODUCTION}

The ability to predict the transfer of water, sediments and nutrients, map catastrophical natural events, identify the radiation balance, biophysical responses

Correspondence to: Adriano Luis Schünemann

E-mail: als@unipampa.edu.br

* Contribution to the centenary of the Brazilian Academy of Sciences. of the environment that influence the landscape and its functions, all have great importance to science and society. Several studies are focused on Earth's surface and its natural resources and changes, especially at the present, when mankind face severe climate changes and widespread modifications of the landscape (Passalacqua et al. 2015).

Passalacqua et al. (2015) defined surveys with high resolution topography (HRT) as any set 
of data in its raw form, consisting of locational measurements $(\mathrm{x}, \mathrm{y})$ and elevations $(\mathrm{z})$, which together make up a cloud of points having spatial resolution greater than or equal to one point per square meter. One of the advantages of HRT surveysis that it enables quantitative study of a phenomena (Tarolli 2014). This is important in zones subjected to strong environmental changes, such as Antarctica, where relief dynamic is highly influenced by physical weathering and permafrost melting (Francelino et al. 2011).

The Digital Elevation Model is a representation of a continuous surface elevation using points with well-known $\mathrm{x}, \mathrm{y}$ and $\mathrm{z}$ coordinates. When the elevation represents the earth surface, it is called Digital Terrain Model (DTM) (Li et al. 2004). The main interpolators to model the landscape or a phenomena, may be grouped in three basic categories as indicated by Wasklewicz et al. (2013): i) local neighborhood (e.g., nearest neighbor, inverse distance weighted, triangulation); ii) geostatistics methods (e.g. kriging), and iii) spline methods.

DTMs can be generated in many ways, such as conventional topographic surveys, kinematic GNSS (Global Navigation Satellite System) surveys, analogue and digital photogrammetric approaches, radar techniques, laser surveys, shipboard echo sounding, airborne optical sensing, satellite radar altimetry, soil augering and geological boring, three-dimensional (3D) seismic survey, airborne ice-penetrating radar techniques, radio-echo sounding surveys and digitizing of contours (Florinsky 2011). The obtained data can be represented as regular grids, square grids, profiles, contouring, regular triangles, hexagons, breaks and feature lines and random forms ( $\mathrm{Li}$ et al. 2004).

Another issue to be studied is focused on the use of processing data. Frequently, the processed data is converted to raster format and later submitted to analysis. However, conversion to the matrix format causes a reduction of detail in the data set, which is avoided by using point cloud, evidenced in the study of Lague et al. (2013). Also, these authors used temporal techniques to evaluate erosion using the point cloud. Despite this previous literature, there is a lack of HRT studies in Polar environments, especially in Maritime Antarctica.

In the past, the topographic representation of the earth's surface was limited to spatial resolutions of up to $10 \mathrm{~m}$, approximately (Hutchinson and Gallant 1999). An example that demonstrates the improvement over the spatial resolution, is the case of SRTM program (Shuttle Radar Topography Mission). Initially, SRTM program had spatial resolution of $90 \mathrm{~m}$ and was later made available a model with spatial resolution of $30 \mathrm{~m}$ (Farr et al. 2007). However, SRTM resolutions would be still insufficient to identify small changes in the landscape, having great importance for numerous environmental phenomena studies. For this reason, the aim of this work was to obtain a high accurate DTM $\left(0.2 \times 0.2 \mathrm{~m}^{2}\right.$ square cell $)$ for Keller Peninsula, Maritime Antarctica. In a near future, the high accurate DTM will be used to map temporal morphometric processes and identify landform changes.

\section{MATERIALS AND METHODS}

\section{STUDY AREA}

The study was carried out at Keller Peninsula (Admiralty Bay, King George Island), Maritime Antarctica, part of the South Shetlands (Fig. 1). The area comprises about $8 \mathrm{~km}^{2}$, being approximately $4 \mathrm{~km}$ of length, considering the north-south direction, and $2 \mathrm{~km}$ of width, considering eastwest direction (Francelino et al. 2011). The altitude reaches up to $380 \mathrm{~m}$ above sea level (Francelino M.R., unpublished data), with an annual average air temperature and rainfall of $-1.8^{\circ} \mathrm{C}$ and $360 \mathrm{~mm}$, respectively (Francelino et al. 2011). The Brazilian Station is placed in this peninsula, which began 


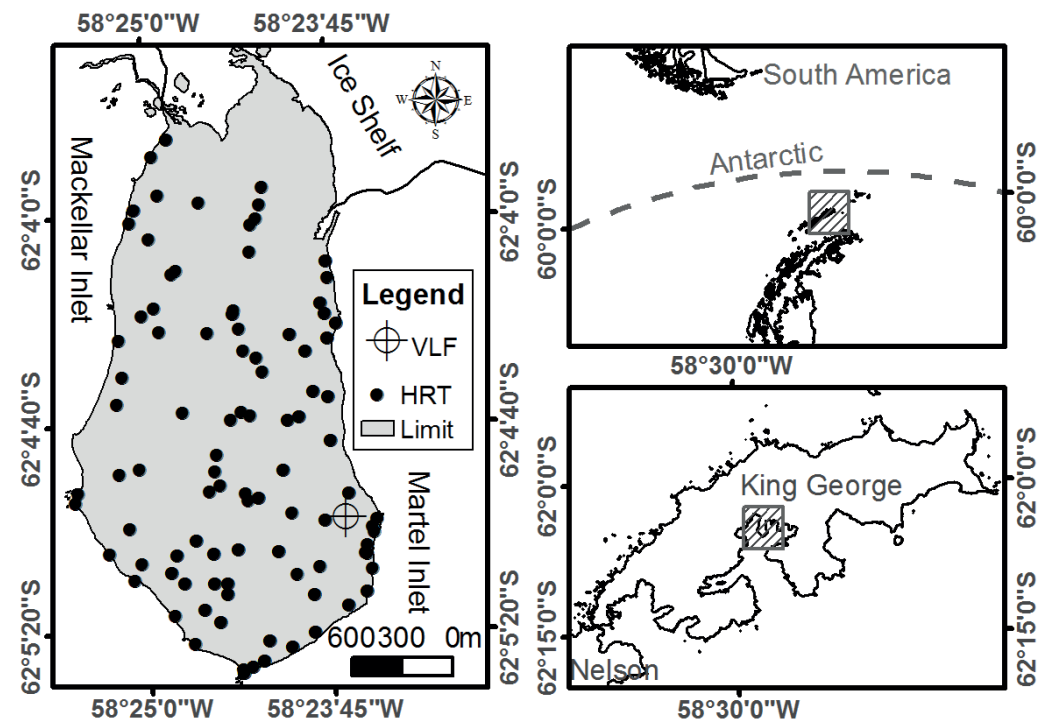

Figure 1 - Illustrative location map of the study area, indicating the stations points (HRT) and the GNSS base (VLF) for post-processing coordinates.

operating in 1984 (Santos et al. 2005). Periglacial Landforms are influenced by physical weathering processes and cryoclasty associated with freezing and thawing cycles, besides strong winds and snow permafrost melting during the summer (Francelino M.R., unpublished data).

\section{HIGH RESOLUTION TOPOGRAPHY SURVEY}

The survey study was assessed in the 2014/2015 and 2015/2016 during the austral summer, by using Terrestrial Laser Scanner (TLS) (RIEGL VZ-1000 model), with a nominal accuracy and precision of 8 and $5 \mathrm{~mm}$, respectively. A GNSS equipment (Leica Model GS80), was used in order to georreference the stations. A base located near the Comandante Ferraz Antarctic Station (Fig. 1) (62 04 ' 58.12 south and $58^{\circ} 23^{\prime} 39.31$ west, and $57.53 \mathrm{~m}$ of ellipsoidal height), was used for differential correction of data.

Due the methodology adopted for scanning survey, sequential surveys were necessary to obtain a minimum overlap of $50 \%$. With this, the concatenation of all measurements generated the point cloud in post-processing. To cover the entire
Peninsula, the TLS equipment was installed in 81 different points as shown in Fig. 1. The scanning survey strategy was designed to cover the largest possible area with an overlap between scanned zones. In areas with high snow cover, the high sensitivity mode of the software was used, to obtain a reasonable density of dots per square meter. The GNSS scans were performed during 10 minutes at each point, where the TLS was also installed, and fixed solutions for all points were obtained.

Results of the HRT-DTM were compared with the DTM generated by Mendes JR et al. (2012). The terrain variables Aspect, Slope, Contour and Hillshade were generated with the two DTMs, and theirs results were also compared.

\section{DATA PROCESSING}

The software Leica Geo-Office was used to process GNSS data (Ramsar Convention Secretariat 2010). All data were referenced with the WGS84 Datum. After obtained the coordinates of all scanned stations, the processing was realized comprising 81 scans from the fixed stations, using the software Riscan Pro 6.1-64 bits version (Bezak et al. 2017). 
The first stage of processing consisted of sequential scans turning for concatenation. This procedure was developed visually, as a routine of the processing. Positions of each scan, do not change on this processing. Later, an adjustment between consecutive and overlapped scans was realized with the tool "Multi Station Adjustment" in the software Riscan Pro. When the standard deviation of error obtained from the adjustment process was lower or equal to $0.040 \mathrm{~m}$, the adjustment process was concluded. However, in some cases, this accurate adjustment could not be obtained, but did not committed the quality of point cloud, since it remained below of the nominal precision of the equipment $(0.080 \mathrm{~m})$. By adjusting the scans, a new cloud was created. The raw cloud has points of objects that are not part of the natural terrain, such as birds and buildings. Also, airborne particles are another issue to be removed from the cloud. Usually, this may be caused by the high-sensitivity mode, as shown in Fig. 2. All these points were manually eliminated from the cloud, in order to obtain the filtered cloud of the terrain.

The entire area was divided into 8 sub-areas, in order to filter the cloud trough the visual filter as well as with an automatic filter so-called "vegetation filter" available in Riscan Pro software. All airbone particles, buildings, shelters, non-terrain features were removed from the raw cloud (routine of the data processing in the software). With this procedure, a new cloud was produced from the merge of the 8 filtered sub-areas, hereafter called "filtered cloud" (FC). The FC comprises 54 points per square meter, which was exported in the ".las" format. After, a "Lasdataset" was created with the ArcGIS 10.1 software (Environmental Systems Research Institute, Redlands CA, USA). The DTM was performed by the generalization of the FC by using "LAS dataset to raster", using average cell recording and "Natural Neighbor" void fill method. The size of the generated cells was $0.20 \mathrm{~m}$.

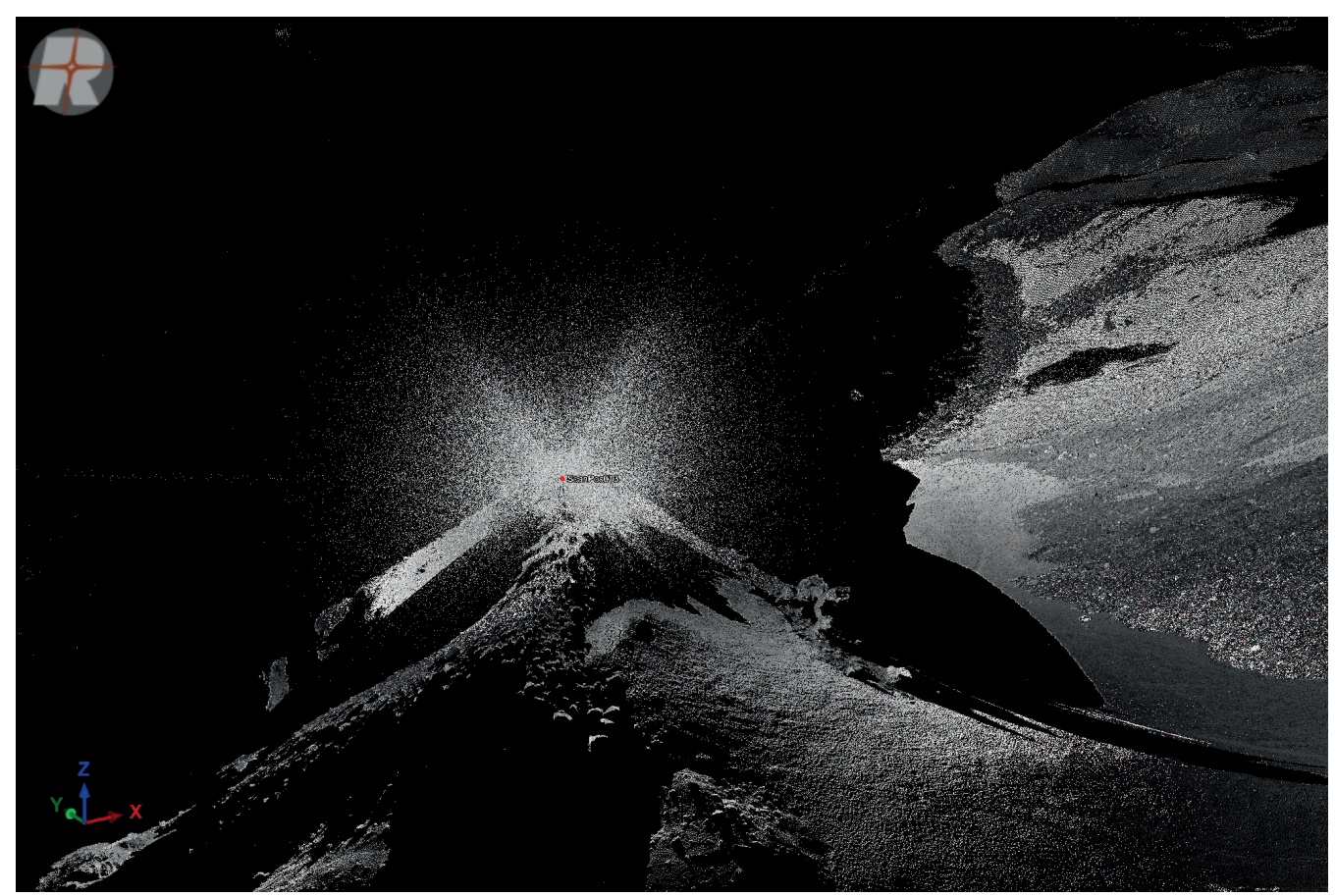

Figure 2 - Cloud with some points (airborne particles registered with high sensibility mode), to be extracted and filtered from the current terrain in the study area. 
Also, altitudes and elevation of the DTM were referenced accordingly to the ellipsoid and local geoid, respectively. The elevation of reference was altered to the local geoid, using the online Geoid Height Calculator (UNAVCO 2016) tool. This process uses the potential coefficient model EGM96 and a set of spherical harmonic coefficients. Finally, the mean Geoid Undulation was obtained for the 81 points, and DTM values were subtracted from the mean Geoid Undulation.

\section{DTM VALIDATION}

An independent GNSS survey was performed to assess the DTM quality. To this end, 57 georeferenced points distributed across the peninsula were obtained. Each point was compared with the DTM generated by using both TLS (HRTDTM), and APG survey (APG-DTM) obtained by Mendes JR et al. (2012). Errors were considered as outliers when values exceeded three times the standard deviation (99.7\%). These errors were excluded on the validation process. The Root Mean Square Error (RMSE) was calculated comparing DTM elevations (HRT-DTM and APG-DTM) with validation points values (57 points), by using the equation below (Willmott and Matsuura 2005):

$$
R M S E=\left[n^{-1} \sum_{i=1}^{n}\left|e_{i}\right|^{2}\right]^{1 / 2}
$$

where

$R M S E=$ root mean square error $(\mathrm{m}) ;$

$e_{i}=$ each difference between DTM elevations and validation points, at an $i$ position (m).

According to the outlier criterion used, 53 validation points were extracted from the HRTDTM. Also, 56 validation points were used to extract the elevation values from the APG-DTM, and then compared with the GNSS points to evaluate the performance. The extractions were performed using R package software (R Development Core Team 2015).

\section{MORPHOMETRIC VARIABLES}

In this study, slope, aspect and hillshade were obtained from the HRT-DTM and APG-DTM. Morphometric variables were generated in the 10.1 ArcGIS software version (Environmental Systems Research Institute, Redlands CA, USA). With this, all morphometric variables were subtracted between HRT-DTM and APG-DTM, and then compared. Hence, these subtractions were considered as errors, which were used to obtain RMSE value.

\section{RESULTS}

\section{CLOUD ADJUSTMENT}

The maximum and minimum standard deviation error obtained from the adjustments was 0.0848 and $0.0081 \mathrm{~m}$, respectively. The mean standard deviation error obtained was $0.0245 \mathrm{~m}$. This value is 4.9 times higher than the nominal accuracy of the equipment. Cell value in this study was generalized based on 2.16 points, approximately. The mean error for latitude, longitude and ellipsoidal height (considering all coordinates) obtained from the GNSS survey in the HRT for TLS stations, were 0.90, 1.63 and $1.9 \mathrm{~mm}$, respectively.

\section{DTMS VALIDATION}

Mean error between the HRT-DTM and the validation point values was $0.718 \mathrm{~m}$, with a standard deviation error of $1.599 \mathrm{~m}$. The threshold to be considered as outliers was $4.796 \mathrm{~m}$. RMSE obtained was $1.740 \mathrm{~m}$ using 57 points. By using outlier criterion, the following points: 48 (error $=$ $5.94 \mathrm{~m}), 55($ error $=6.06 \mathrm{~m}), 59($ error $=6.04 \mathrm{~m})$ and 65 (error $=6.01 \mathrm{~m})$ were excluded from the validation cloud in HRT-DTM (Fig. 3). With this criterion, RMSE decreased, reaching to $0.726 \mathrm{~m}$.

The APG-DTM validation showed mean error of $2.044 \mathrm{~m}$, which is higher than HRT-DTM. Slightly elevated standard deviation error (4.458 m) was obtained for the APG-DTM validation 

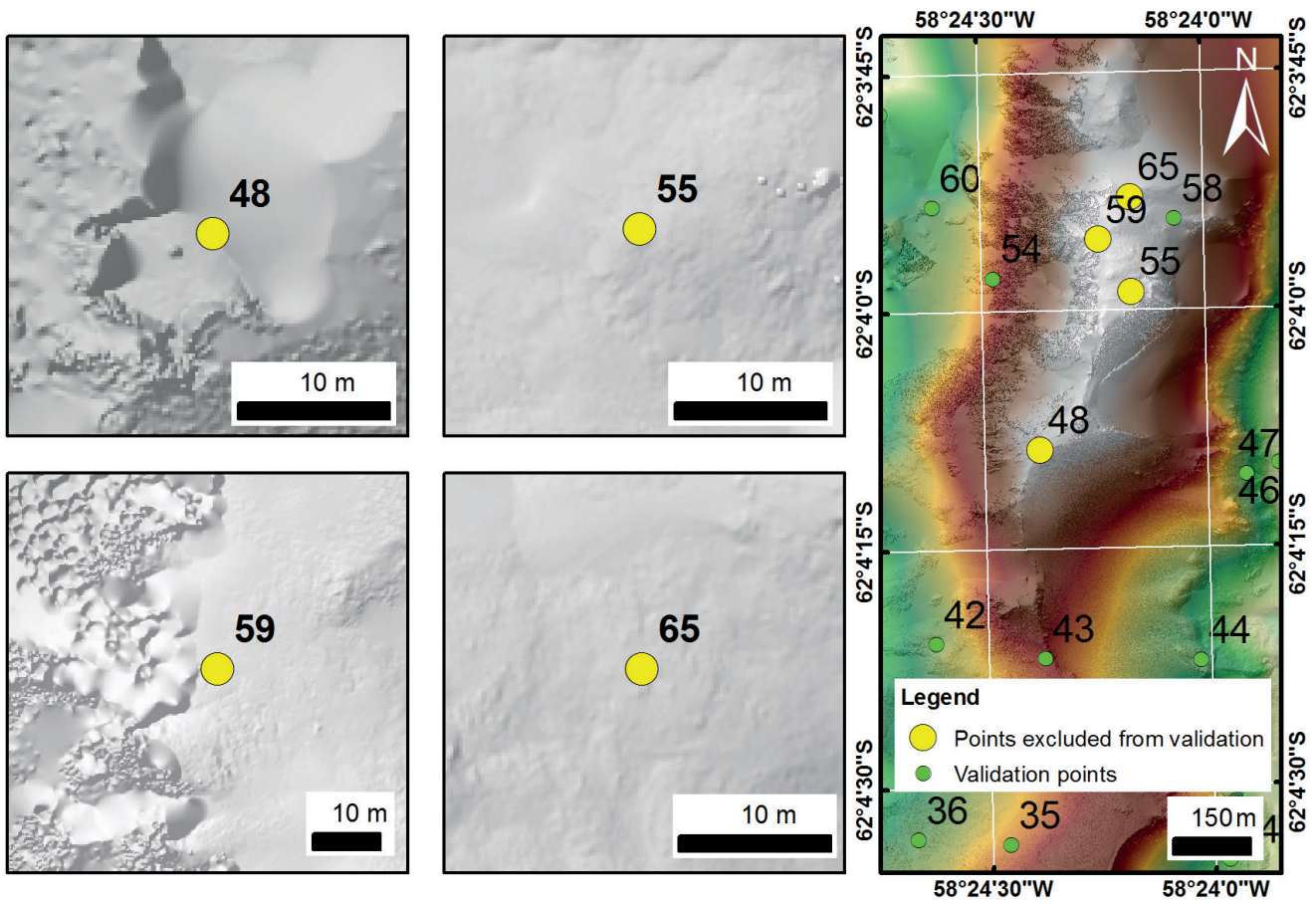

Figure 3 - Points considered as outliers for HRT-DTM.

when compared with HRT-DTM. In addition, RMSE value was $4.868 \mathrm{~m}$, using 57 points. Using the same criterion to eliminate the outliers, only the point 47 (error $=32.080 \mathrm{~m}$ ) (Fig. 4) was excluded from the validation data. With this, a value of 2.397 $\mathrm{m}$ was obtained, which is more than 3 times higher than HRT-DTM procedure considered.

\section{DIGITAL TERRAIN MODEL (DTM)}

The DTM generated with the HRT survey is shown in Fig. 5. The maximum elevation value recorded was $331.503 \mathrm{~m}$ at the Mount Birkenmajer. Flat areas are located on locations closer to the sea level, especially on the west side.

\section{MORPHOMETRIC VARIABLES COMPARISON}

Clearly, morphometric variables obtained from the two methods present differences on the thematic maps in Fig. 6, Fig. 7 and Fig. 8. According to the RMSE, a contrast exists between the two surveys. An amount of 82.184 (with the same units of the raster) was recorded for the Aspect. Visually, Aspect in the HRT-DTM showed a better representation when compared with the APG-DTM (Fig. 6).

For the Slope, a RMSE of 67.725 (percent rise) was obtained, comparing the two methods. Thematic maps of slope can be viewed in Fig. 7, where a marked difference on the accuracy in the HRT-DTM is observed. In addition, a difference of 48.796 between HRT-DTM and APG-DTM was recorded, for the generated hillshades. The visual comparison of the two positions is presented in Fig. 8 .

Results indicated a RMSE of $10.510 \mathrm{~m}$ when comparing HRT-DTM and APG-DTM methods, indicating difference on terrestrial modeling performance.

\section{DISCUSSION}

This is the first detailed survey using a high resolution topography equipment (laser scanner) in ice-free areas in Maritime Antarctica. Previously, studies of Francelino M.R. (unpublished data) and Mendes 


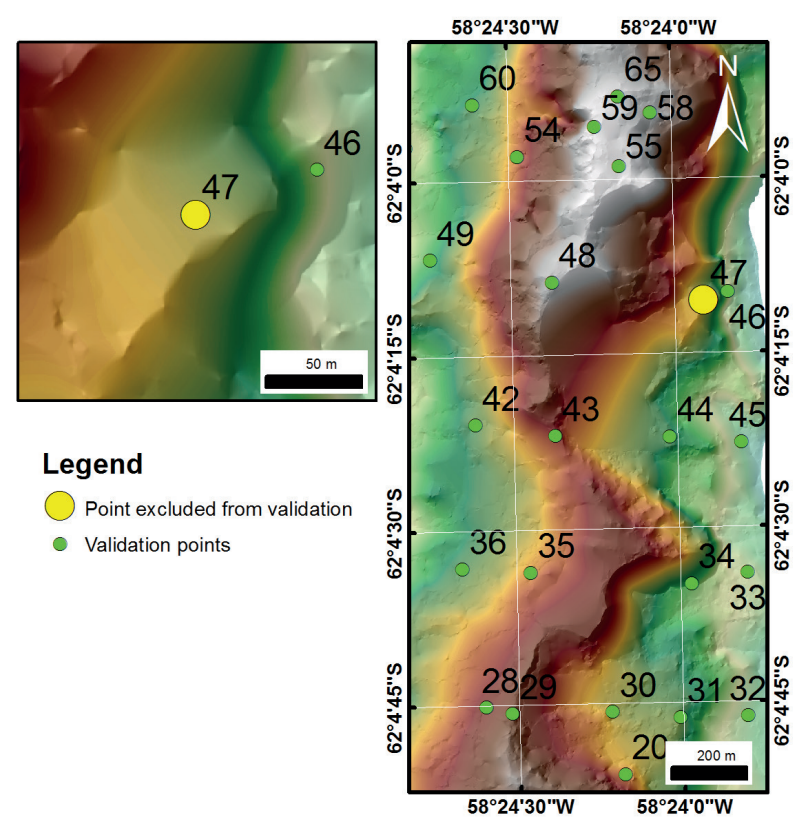

Figure 4 - Point considered as outliers for APG-DTM.

Jr et al. (2012) developed digital elevation models and morphometric variables and topographic maps based on APG and GNSS surveys. In these studies, the authors used interpolation as a main process to obtain digital elevation models, in order to generate terrain attributes. Mendes Jr et al. (2012) used 70,787 points derived from the stereomodel, combined with the data from the EACF topographic plan (Erwes et al. 2012) to obtain the DTM. Despite being the first work in this region, the DTM does not have enough resolution to characterized small variations on relief. This is important to evaluate landscape modification in para- and periglacial zones, which are in constant changes, especially in Maritime Antarctica, subjected to more humid and warm climate conditions. In a small period of monitoring, these changes could be observed by using a HRT method, such as the laser scanner.

In this work, approximately 270 million of points (about 54 points per square meter) were used to obtain the DTM for the Keller Peninsula, representing the more detailed terrestrial modeling documented in Maritime Antarctica yet. Overall, the main process to elaborate the DTM was generalization. The interpolation method predicts values for cells in a raster from a limited number of sample data points, while generalization calculates values for cells from several set of data within the same cell. Cell value in this study emphasizes the precision of the method chosen to model the surface. Interpolation method was the main process used in the APG-DTM modeling, because only a few points per square meters (less than 1 point per square meter) were available in the studied area, explaining the better performance of the HRTDTM.

Although generalization was the main process, in some places interpolation also occurred. This is due for the fact that laser scanner did not accessed surfaces with snow, ice or lack of overlap during

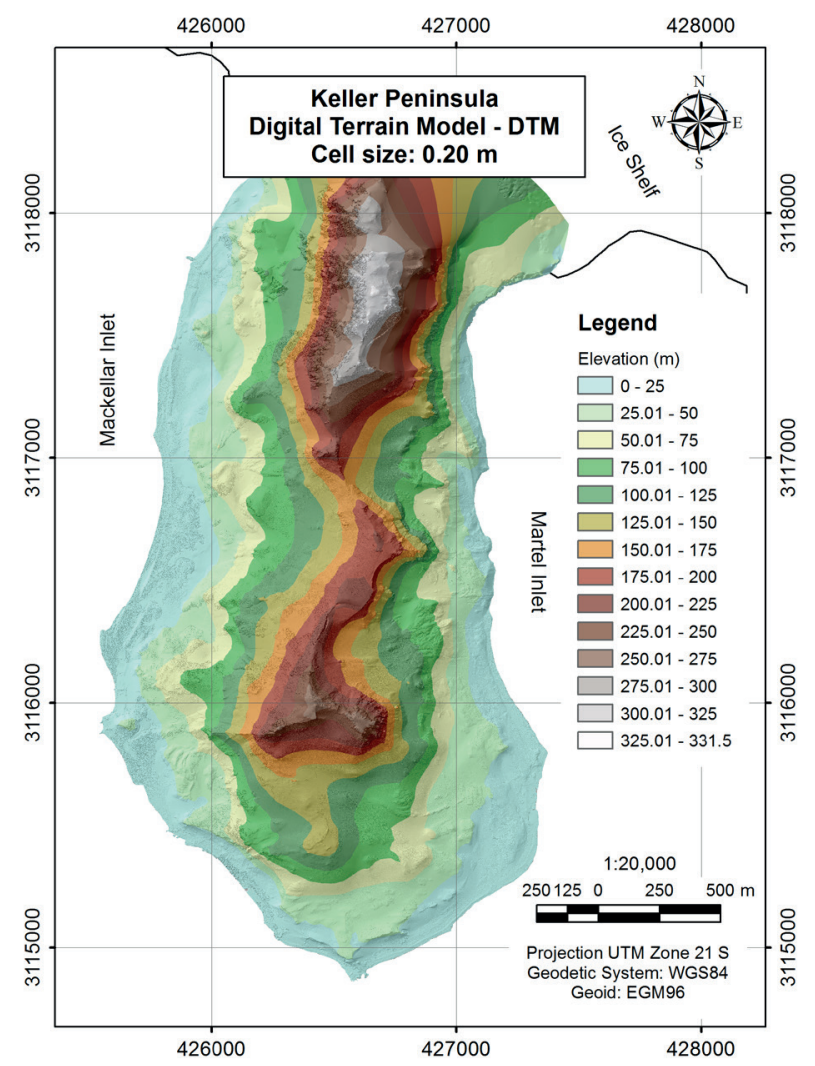

Figure 5 - Digital Terrain Model of Keller Peninsula with $0.20 \mathrm{~m}$ cell size (HRT-DTM)(http://terrantar.ufv.br/ geonetwork/srv/en/resources.get?uuid=719D2E19-95F943AC-A35E-953B2738DA1E\&fname=MDT_Keller_2016. zip\&access $=$ private). 

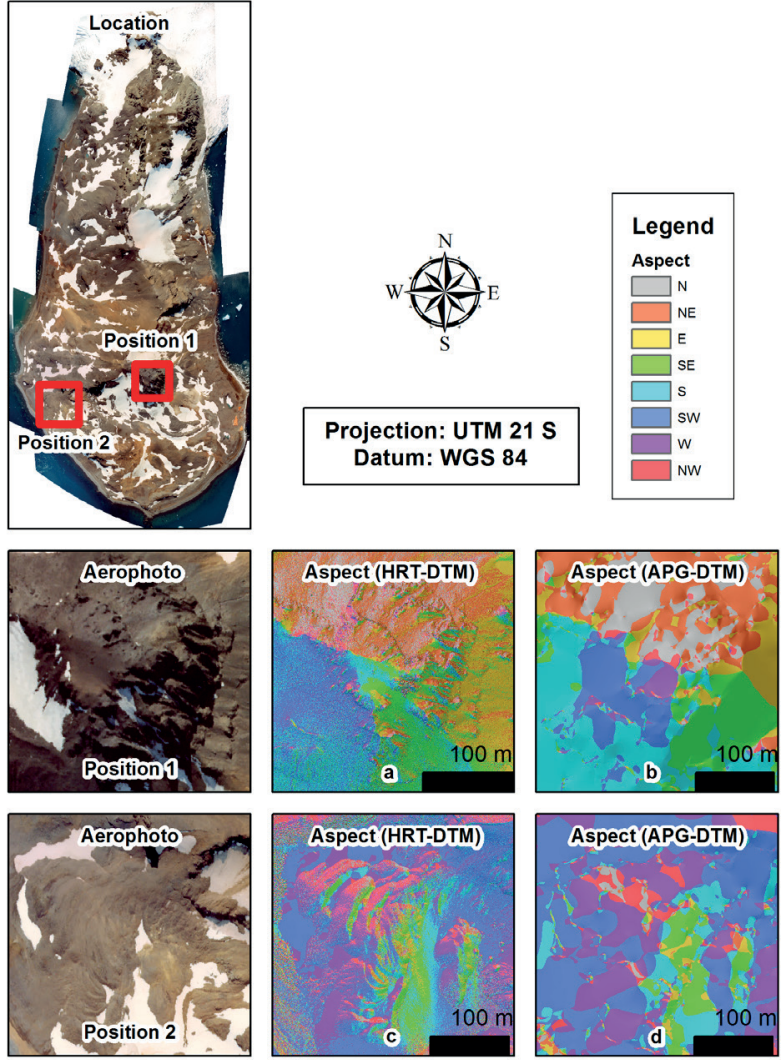

Figure 6 - Illustrative representation of the Aspect for the HRT-DTM (a and c) and the APG-DTM (b and d) in two different positions (Aerophotos adapted from Francelino M.R., unpublished data).

survey, resulting in empty zones in the cloud. Hence, the regions of the points 48, 55, 59 and 65 (Fig. 3) were modeled by interpolation instead of generalization. Results also indicated differences of altitude values in the highest peak in Keller Peninsula. In this work, the highest peak in Keller Peninsula presented $331.503 \mathrm{~m}$,compared with 332.786 above the sea level (asl), reported by Mendes Jr. et al. (2012), and $380 \mathrm{~m}$ asl, by Francelino et al. (2011). This result is mainly related to the differences in the generalization and interpolation methods, indicating an overestimation when using interpolation as a main method to generate DTM.

During the HRT processing, the cloud adjustments did not suffer influence of the GNSS survey, since GNSS positions were considered

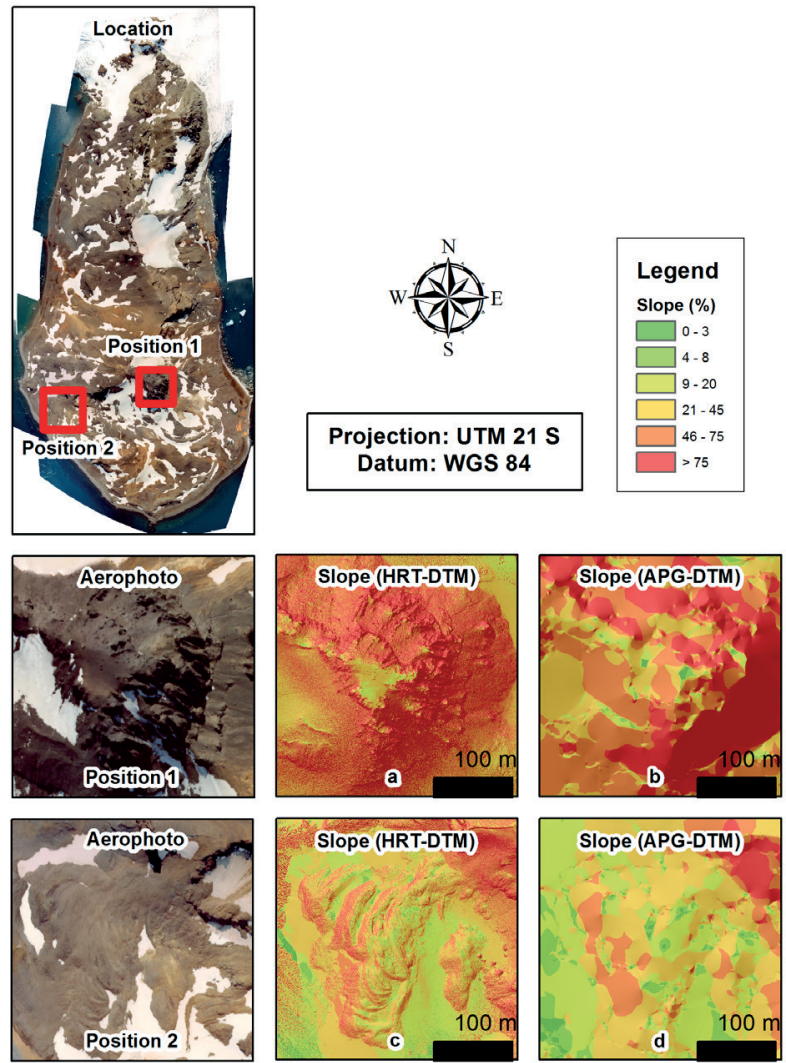

Figure 7 - Illustrative representation of the Slope for the HRT-DTM (a and c) and the APG-DTM (b and d) in two different positions (Aerophotos adapted from Francelino M.R., unpublished data).

fixed on the adjustment, varying only $\Delta \mathbf{R o l l}$, $\Delta$ Pit and $\Delta$ yaw (adjustment parameters). By eliminating outliers by using statistical criteria, RMSE tended to decrease in both surveys (HRTDTM and APG-DTM), improving the quality of the modeling. RMSE is reported to be an efficient indicator of modeling performance (Mendes $\mathrm{Jr}$ et al. 2012). RMSE decreased up to $49 \%$ when eliminating outliers in the APG-DTM. RMSE values indicated differences among morphometric variables. However, in this case, the significance of the differences was not quantified. Qualitatively, visual performance was clearly identified in Fig. 6, Fig. 7 and Fig. 8 for morphometric variables and in Fig. 9 for DTM. With this, the visual quality of the thematic maps is more pronounced in the HRT- 

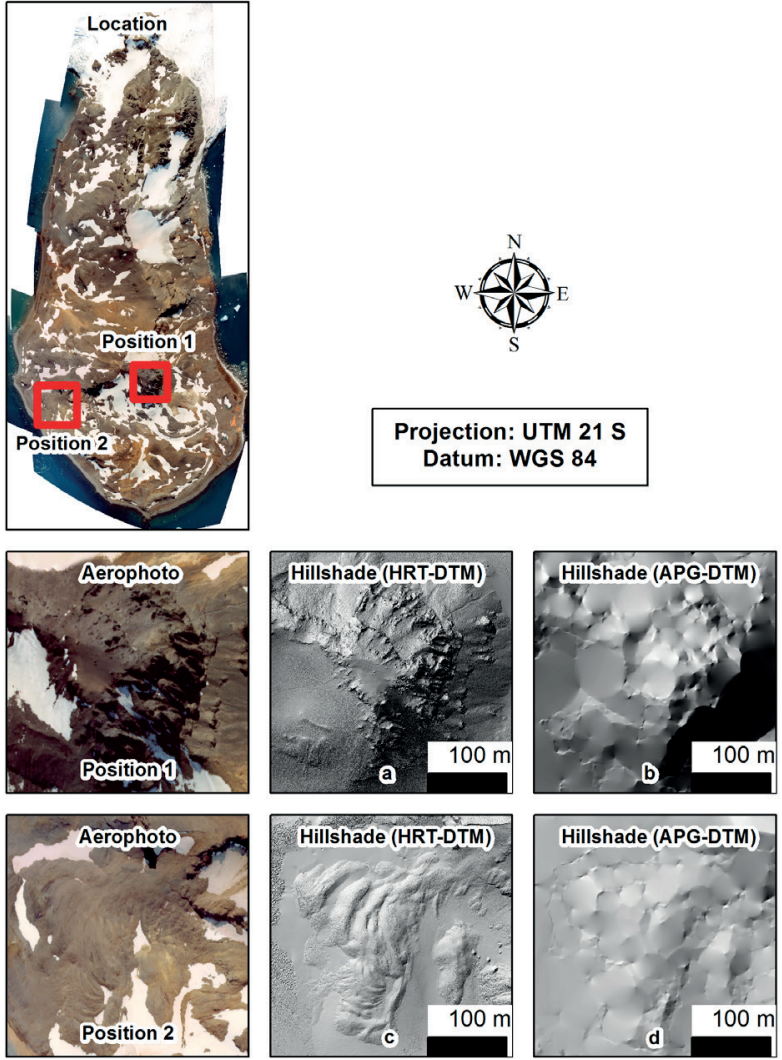

Figure 8 - Illustrative representation of the Hillshade for the HRT-DTM (a and c) and the APG-DTM (b and d) in two different positions (Aerophotos adapted from Francelino M.R., unpublished data).

DTM maps, due the elevated number of points used to model the surface.

\section{CONCLUSIONS}

High-resolution topography represents an efficient tool to map landscapes in ice-free areas in Maritime Antarctica. Digital terrain models obtained by generalization as a main process, present lower root mean square error, with elevated number of points per cell in comparison with those generated by interpolation. A large number of points can be obtained by using laser scanner, providing a dense cloud of points, well-spatially distributed, enabling the generalization process to obtain surface models with high performance. Hence, morphometric variables can be detailed mapped and studied,
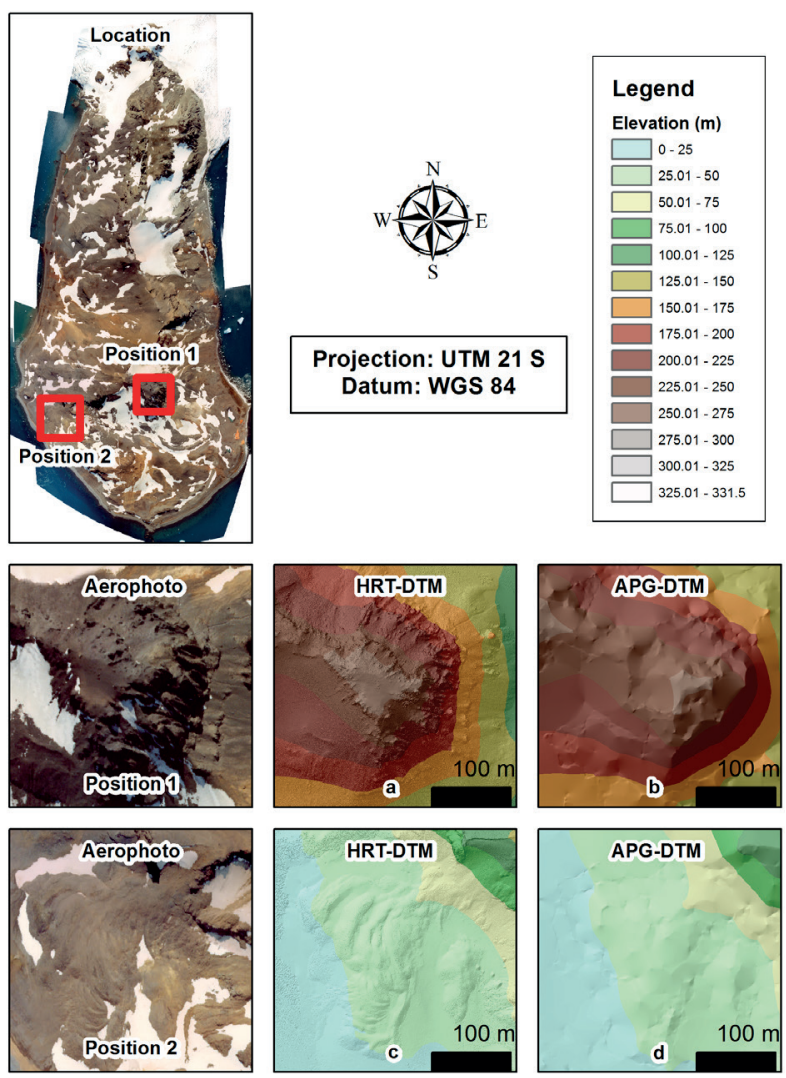

Figure 9 - Illustrative representation of the DTM generated by HRT-DTM (a and c) and the APG-DTM (b and d) methods, in two different positions (Aerophotos adapted from Francelino M.R., unpublished data).

accurately representing the local relief. Also, this technique allows studies of landscape evolution at a micro scale in time, in which geomorphological process can be assessed. The modeling of similar periglacial landscapes in Maritime Antarctica must be achieved, in order to better understand landscape changes in polar zones under current climate warming.

\section{ACKNOWLEDGMENTS}

We acknowledge Conselho Nacional de Desenvolvimento Científico e Tecnológico (CNPq) (556794/2009-5) and Ministério da Ciência, Tecnologia e Inovação (MCTI) for granting financial support. This work is a contribution of INCT-Criosfera TERRANTAR group. Thanks for 
the Project Geoespaço (http://www.inpe.br/crs/ pan/pesquisas/geoespaco.php), process CNPq/ PROANTAR: 556872/2009-6, for the GNSS base data. We thank Universidade Federal do Pampa for support.

\section{REFERENCES}

BEZAK B, GRIGILLO D, URBANČIČ T, MIKOŠ M, PETROVIČ D AND RUSJAN S. 2017. Geomorphic response detection and quantification in a steep forested torrent. Geomorphology 291: 33-44.

ERWES HJB, PRADO WS, FAZAN JA, FONSECA JR ES AND MENDES JR CW. 2012. Topographic survey and photogrammetric documentation of the Brazilian Antarctic Station Comandante Ferraz. Pesq Antart Bras 5: 95-103.

FARR TG ET AL. 2007. The shuttle radar topography mission. Rev Geophys 45: RG2004 doi:10.1029/2005RG000183.

FLORINSKY IV. 2011. Digital terrain analysis in soil science and geology. Academic Press, $1^{\text {st }}$ ed., p. 31-41.

FRANCELINO MR, SCHAEFER, CEGR, SIMAS FNB, FERNANDES-FILHO EI, SOUZA JJLL AND COSTA LM.2011. Geomorphology and soils distribution under paraglacial conditions in an ice-free area of Admiralty Bay, King George Island, Antarctica. Catena 85(3): 194-204.

HUTCHINSON MF AND GALLANT JC. 1999. Representation of terrain. Geographical information systems: principles and technical issues. Wiley, v. 2, p. 105-124.

LAGUE D, BRODU N AND LEROUX J. 2013. Accurate 3D comparison of complex topography with terrestrial laser scanner: Application to the Rangitikei canyon (N-Z). ISPRS J Photogramm 82: 10-26.

LI Z, ZHU Q AND GOLD C. 2004. Digital Terrain Modeling: Principles and Methodology. Publisher: CRC PRESS, Washington, D.C., USA, p. 65-85.
MENDES JR CW, DANI N, ARIGONY-NETO J, SIMÕES JC, VELHO LF, RIBEIRO RR, PARNOW I, BREMER UF, FONSECA-JÚNIOR ES AND ERWES HJB. 2012. A new topographic map for Keller Peninsula, King George Island, Antarctica. Braz Antarc Res 5: 105-113.

PASSALACQUA P ET AL. 2015. Analyzing high resolution topography for advancing the understanding of mass and energy transfer through landscapes: A review. Earth-Sci Rev 148: 174-193.

R DEVELOPMENT CORE TEAM. 2015. R: A Language and Environment for Statistical computing. R Foundation for Statistical Computing, Vienna Austria. http://www.Rproject.org.

RAMSAR CONVENTION SECRETARIAT. 2010. River basin management: Integrating wetland conservation and wise use into river basin management. Ramsar handbooks for the wise use of wetlands, $4^{\text {th }}$ ed., v. 9. Ramsar Convention Secretariat, Gland, Switzerland.

SANTOS IR, SILVA-FILHO EV, SCHAEFER CEGR, ALBUQUERQUE-FILHO MR AND CAMPOS LS 2005. Heavy metal contamination in coastal sediments and soils near the Brazilian Antarctic Station, King George Island. Mar Pollut Bull 50(2): 185-194.

TAROLLI P. 2014. High-resolution topography for understanding Earth surface processes: Opportunities and challenges. Geomorphology 216: 295-312.

UNAVCO. 2016. Available online: https://www.unavco.org/ software/geodetic-utilities/geoid-height-calculator/geoidheight-calculator.html (accessed on 09/08/2016).

WASKLEWICZ T, STALEY DM, REAVIS K AND OGUCHI T. 2013. 3.6 Digital Terrain Modeling. In: Treatise on Geomorphology, p. 130-216.

WILLMOTT CJ AND MATSUURA K. 2005. Advantages of the mean absolute error (MAE) over the root mean square error (RMSE) in assessing average model performance. Climate Res 30(1): 79-82. 